\title{
TXTTaofiTapaa: pilot trial of a Samoan mobile phone smoking cessation programme
}

\author{
Robyn Whittaker', Elaine Umali', Helen Tanielu' ${ }^{3}$, Judith $\mathrm{McCool}^{2}$ \\ 1 National Institute for Health Innovation, School of Population Health, University of Auckland, Auckland, New Zealand, 2 Epidemiology and \\ Biostatistics, School of Population Health, University of Auckland, Auckland, New Zealand, ${ }^{3}$ National University of Samoa, Apia, Samoa \\ Keywords: global health
}

https://doi.org/10.29392/joghr.3.e2019035

\section{Journal of Global Health Reports}

Vol. 3, 2019

\section{Background}

Smoking remains a major risk factor to good health across the Pacific region. Samoa, like other Pacific nations, has signed up to the Framework Convention on Tobacco Control (FCTC) to reduce the prevalence through actions including providing smoking cessation services. A text message cessation programme that had been proven successful in New Zealand was adapted and trialled in Samoa. The aims of this study were to trial the Samoan mCessation programme TXTTaofiTapaa to determine the feasibility, acceptability and potential to help smokers in Samoa to quit.

\section{Methods}

One hundred smokers across Samoa were recruited to the trial but early technical issues meant not all received the programme immediately and therefore were not able to be followed up.

\section{Results}

Of the 72 participants providing follow up data, 28 (38.9\%) reported abstinence for at least seven days at 1-month follow up. In addition, 68 (94.4\%) said they liked the programme, 61 (84.7\%) said they thought it would be effective for Samoans, 67 (93.1\%) said they would recommend the programme to others, and 37 (15.9\%) said that it helped them to try to quit smoking at least once.

\section{Conclusions}

Delivering a text message cessation programme (TXTTaofiTapaa) in Samoa is feasible, and smokers in Samoa appear to find it to be both acceptable and helpful.

\section{Implications}

This study adds to our knowledge about the adaptation of proven effective technology based smoking cessation interventions from high income countries with multifaceted tobacco control strategies, to different contexts. In this case, dealing with differences in culture, language, and the tobacco control environment.

Smoking is a major risk factor for preventable morbidity and mortality across the 22 Pacific Island countries and territories (PICTs). ${ }^{1-3}$ Its impact weighs heavily on the health care system and economies that are already under significant financial constraints. Samoa is a country in the Pacific region where tobacco smoking has declined over the past decade, ${ }^{4}$ but remains high with approximately $26 \%$ of adults reported to be smokers in 2013.5 A recent review of smoking prevalence in Samoa describes a steady decline in tobacco use among males and females (39.5\% and $16.8 \%$ respectively in 2013). ${ }^{5}$ Despite this progress, considerable effort is necessary to achieve both the World Health Organization's (WHO) Western Pacific Regional target of a 10\% reduction in tobacco use, ${ }^{6}$ and national objectives to reduce non-communicable diseases (NCDs). ${ }^{7}$ Cessation support is one area that may assist Samoa to reach this target, and importantly, reduce the health related consequences of tobacco use.

We worked with the Samoa Ministry of Health $(\mathrm{MoH})$ and the Samoa Cancer Society to adapt a text-based mobile smoking cessation (mCessation) program proven effective in New Zealand and other countries ${ }^{8-10}$ for the Samoan context. The adaptation process has been described in detail elsewhere. ${ }^{11,12}$ Briefly, the adaptation process started with a series of focus groups with smokers in Samoa to understand local perceptions of smoking and quitting. The text messages developed in New Zealand were first trialled among a sample of smokers and ex-smokers in Samoa in the 
first phase of a participatory iterative process of adapting, testing and re-testing a Samoan specific mCessation programme. Linguistic as well as traditional Samoan lifestyle (fa'a Samoa) references (i.e., inclusions of family over individual benefits of quitting), were considered in the adaptation. The initial translation into Samoan language required multiple iterations created in partnership with the Samoa $\mathrm{MoH}$.

The rationale for adapting existing mhealth programmes for new jurisdictions is based on an appreciation that, with modifications, the foundations of behaviour change are universal and can be applied across different settings. Although the universality of behaviour change theory is a subject of discussion, a distinct advantage of mHealth (using mobile phones for delivery) is that it lends itself to adaptation. The caveats include the existence of a robust telecommunications infrastructure, supportive mobile network operator (MNO) and the willing participation of the population.

We present the results of a trial where a mCessation program called TXTTaoafiTapaa (TxtStopSmoke) was adapted and trialled for use in Samoa. Samoa was well placed to participate in this program; a relatively high tobacco prevalence rate, ${ }^{5}$ high mobile phone ownership, ${ }^{13}$ and a predominantly young population. ${ }^{14}$ In addition, Samoa at this time was at the early stage of developing a smoking cessation plan, with nicotine replacement therapy available (although not subsidized) and smoking cessation not yet widely socialised.

This study aimed to test the TXTTaofiTapaa programme with respect to feasibility, acceptability and potential for effectiveness. To this aim, the research questions were:

- Is it feasible to deliver a text message health contentbased programme in Samoa?

- Is an mCessation programme that has been locally adapted from a New Zealand developed programme acceptable to Samoan smokers?

- Is a locally adapted mCessation programme likely to be effective in Samoa?

\section{METHODS}

\section{DELIVERY OF MCESSATION SUPPORT}

The programme was delivered by Bluesky Telecommunications Ltd (a local MNO with operations across Samoa, American Samoa and Cook Islands) in collaboration with the Samoa MoH and New Zealand developers at the University of Auckland. The programme was developed in Drupal, an open-source content management system (CMS), and run on a local web server hosted by Bluesky. Bluesky worked with the only other MNO in Samoa to deliver messages to all participants regardless of provider. However, this initially failed and participants who were not with Bluesky did not start receiving the programme as intended. This required a technical fix between the two MNOs and took considerable time before the remaining participants could be connected and then receive the entire programme.

\section{PARTICIPANT RECRUITMENT}

Participants in the study were recruited by a Samoa-based research assistant (RA) employed by the Samoa $\mathrm{MoH}$ and trained by the New Zealand researchers. Posters were placed in high people traffic areas such as churches, community centres and transport terminals. The trial was also promoted directly within workplaces, and consenting participants could then register for the trial immediately onsite. Recruitment flyers were distributed during Samoa $\mathrm{MoH}$ organised community outreach clinics. A Facebook post was also shared on the Samoa Cancer Society Facebook page.

The participant inclusion criteria included: current daily smoker who wants to quit, owns a personal mobile phone (not shared), aged 16 years or older, able to provide informed consent, able to read and speak Samoan or English, and available for the duration of the trial. The posters provided the contact number of the local research assistant.

\section{PROCEDURES AND INTERVENTION}

Interested participants were asked to text an allocated study number and the local RA responded and arranged a time to make contact with them (over the phone or faceto-face). The RA provided information about the study and conducted a preliminary interview to assess eligibility. Those who did not meet the inclusion criteria were referred to the Samoa MoH for information on how to quit smoking. Eligible participants were provided hard copies of the consent form. Once the potential participant agreed to complete the trial, the RA scheduled a time to meet to complete the consent form and a baseline questionnaire, which collected the participants' demographics, mobile phone number, tobacco and media use. After completion of the baseline questionnaire, all participants received 20 Samoan tala (approximately US\$8) in recognition of their time and transport costs.

Once baseline data collection was complete, participants were registered on the TXTTaofiTapaa programme. Once registered, the participants received a series of countdown messages helping them to prepare for their quit day, followed by messages providing motivation plus practical suggestions on how to stay quit. The full 92 text messages were sent over a 12-week period, with varying frequency (Figure 1). The programme was available in either English or Samoan according to participants' preference.

Participants were free to withdraw from the trial at any time by texting back the word STOP. Texting in the word 'stop' automatically stops the programme from sending any further programme text messages. Participants who opted out were still contacted to complete the post-programme evaluation questionnaire.

A media campaign was simultaneously aired alongside the mCessation programme in order to increase awareness about the negative effects of tobacco smoking and to increase interest and demand for a smoking cessation support programme. The media campaign was based on a previous successful campaign of the New York City Department of Health and Mental Hygiene called "Cigarettes are Eating You Alive" and adapted to Samoan audiences. It included three 30 -second advertisements broadcasted on national 


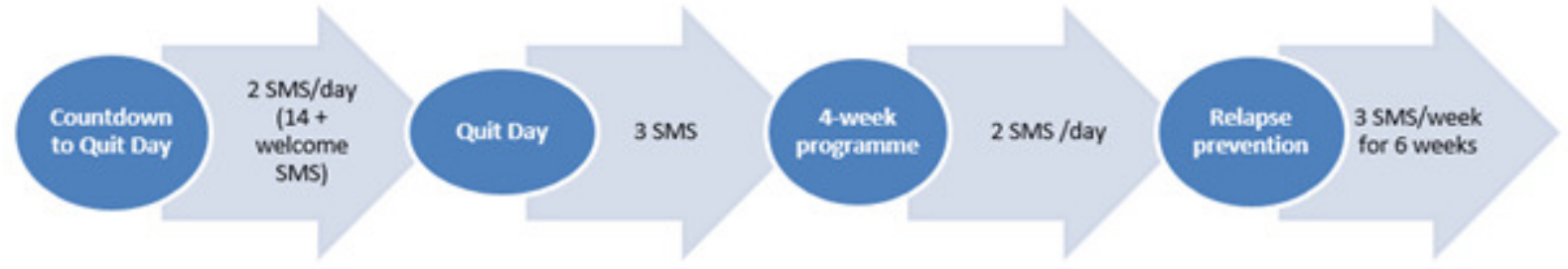

Figure 1. The TXTTaofiTapaa Programme.

SMS (Short Message Service) - text messages.

television and radio stations in Samoa for three months (simultaneous with the recruitment and enrolment to the mCessation programme).

After programme completion at 12 weeks, a follow-up assessment was conducted (over the phone or face-to-face) where the participants received another 20 Samoan tala (less than US\$8).

\section{DATA COLLECTION AND MEASURES}

The participants completed a baseline survey questionnaire to gather demographic information, a nominated mobile phone number, language preference for the SMS and the name to appear on the personalized text messages. Participants reported smoking habits at baseline and at follow-up. Smoking habits were assessed utilizing a modified Fagerström Test for Nicotine Dependence. We utilized 5 of the 6-point scale, removing question 2 (Do you find it difficult to refrain from smoking in places where it is forbidden?) to avoid confusion among participants as smoke-free areas were not yet fully implemented during trial. Nicotine dependence was then categorized into the following threepoint measures: low $(1,2)$, medium (3-6) and high (7+). Smoking cessation at follow-up was self-reported. Participants who responded "No" to the question "Have you smoked a cigarette in the last seven days?" were considered to have successfully stopped smoking. The number of quit attempts during the trial and any other cessation support used were collected, as well as more in-depth information around the level of satisfaction with the programme and whether any technical issues were experienced.

\section{ETHICS APPROVAL}

Ethical approval for this study was obtained from the University of Auckland Ethics Committee (reference 016631) and the Samoa Ministry of Health Research Committee.

\section{RESULTS}

One hundred participants were recruited across Samoa in two months. Recruitment sources were: $51.9 \%$ from the workplace or co-workers, and $23 \%$ from other sources $(9.3 \%$ flyers, $4.6 \%$ from posters, $5.6 \%$ school and community outreach, 3.7\% Facebook). Enrolled participants started receiv- ing messages in batches starting in July 2016. The baseline characteristics of recruited participants are described in Table 1.

A total of 55 participants were able to complete the initial post-programme survey. However, due to technical issues between the two MNOs, 37 participants who were not Bluesky subscribers received only 1-2 weeks of text messages (Figure 2). These participants were contacted as soon as the issue was resolved and were offered the programme. Twenty-four (24) participants took up this offer and received the full programme albeit later than the other participants. Thirteen (13) were not contactable or refused the programme at that time. Only 17 out of the 24 re-enrolled participants were able to be complete the post-programme survey, the other 7 were lost to follow. In total, 72 participants were able to complete the post-programme survey for this trial.

Follow up data at one month is available for 72 participants. Of those 72 participants, 28 (40\%) stated that they had not had a cigarette in the past seven days (7-day selfreported point prevalence abstinence).

Of those who had smoked ( $\mathrm{n}=44), 33$ (75\%) now smoked on average 10 or less cigarettes, 6 smoked 11-20 cigarettes, 3 smoked 21-30 cigarettes, and 2 smoked more than 30 . Most $(35,80 \%)$ said they had attempted to stop smoking during the programme (16 [36\%] once, 19 [43\%] more than once).

All participants were asked about how the programme may have helped them (Table 2).

Twenty-three participants (32\%) said they had experienced problems receiving the programme. These included not receiving all of the text messages (18, 72\%), losing their phone $(4,16 \%)$, changing mobile numbers $(1,4 \%)$, not understanding the words $(1,4 \%)$ and not receiving any messages $(1,4 \%)$. When asked how many of the messages they actually read, 51 (71\%) said they read all of the messages, 15 (21\%) said they read most, 3 (4\%) said they read about half of the messages, and 3 (4\%) said they only read a few.

Most participants $(67,93 \%)$ said they would recommend the programme to others. When asked specifically, 61 (85\%) felt the programme is effective for Samoans, 7 (10\%) stated it is not effective for Samoans and 4 (6\%) answered maybe (Table 3). The reasons stated for not being effective included: messages were too general/not strong enough; 
Table 1. Baseline characteristics

\begin{tabular}{|c|c|c|}
\hline & $N=100$ & $\%$ \\
\hline Female & 40 & 40 \\
\hline \multicolumn{3}{|l|}{ Residence: } \\
\hline Apia (capital) & 79 & 79 \\
\hline Outside Apia & 21 & 21 \\
\hline \multicolumn{3}{|l|}{ Telecom provider: } \\
\hline Bluesky & 30 & 30 \\
\hline Digicel & 70 & 70 \\
\hline \multicolumn{3}{|l|}{ Language preference in TXTTaofiTapaa: } \\
\hline Samoan & 49 & 49 \\
\hline English & 51 & 51 \\
\hline \multicolumn{3}{|c|}{ Fagerstrom classification of nicotine dependence: } \\
\hline Low dependence & 15 & 15 \\
\hline Moderate dependence & 58 & 58 \\
\hline High dependence & 15 & 15 \\
\hline Incomplete answers & 12 & 12 \\
\hline \multicolumn{3}{|l|}{ On average, number of cigarettes per day: } \\
\hline 10 or less & 45 & 45 \\
\hline 11 to 20 & 31 & 31 \\
\hline 21 to 30 & 14 & 14 \\
\hline 31 or more & 10 & 10 \\
\hline \multicolumn{3}{|l|}{ Time to first cigarette in the morning: } \\
\hline Within 5 minutes & 49 & 49 \\
\hline 6-30 minutes & 24 & 24 \\
\hline $31-60$ minutes & 1 & 1 \\
\hline After 60 minutes & 26 & 26 \\
\hline \multicolumn{3}{|c|}{ Number of serious quit attempts in last 12 months: } \\
\hline One & 30 & 30 \\
\hline More than one & 28 & 28 \\
\hline Nil & 42 & 42 \\
\hline \multicolumn{3}{|c|}{ If attempts in past 12 months, support used: } \\
\hline None & 35 & 60 \\
\hline Counselling & 8 & 14 \\
\hline Doctor's advice & 3 & 5 \\
\hline Church & 1 & 2 \\
\hline Gym & 1 & 2 \\
\hline No answer & 10 & 17 \\
\hline \multicolumn{3}{|c|}{ Barriers to quitting: (could choose more than one) } \\
\hline I enjoy smoking too much & 52 & 26 \\
\hline I don't believe I can do it & 4 & 2 \\
\hline I have many friends/family who smoke & 56 & 28 \\
\hline I lack support from friends/family & 4 & 2 \\
\hline $\begin{array}{l}\text { I don't believe smoking is really } \\
\text { harmful }\end{array}$ & 3 & 2 \\
\hline If I quit I will gain weight & 17 & 8 \\
\hline I have too much stress in my life now & 41 & 20 \\
\hline $\begin{array}{l}\text { I can stop without this programme } \\
\text { some day }\end{array}$ & 7 & 3 \\
\hline It's an addition/habit & 16 & 8 \\
\hline
\end{tabular}

\begin{tabular}{lcc}
\hline & $\mathrm{N}=100$ & $\%$ \\
\hline Other & 3 & 2 \\
How likely they will be smokefree in one year: & & \\
1 - very unlikely & 2 & 2 \\
2 & 5 & 5 \\
3 & 5 & 5 \\
4 & 4 & 4 \\
5 & 20 & 20 \\
6 & 8 & 8 \\
7 & 5 & 5 \\
8 & 0 & 0 \\
9 & 9 & 9 \\
$10-$ very likely & 42 & 42 \\
\hline
\end{tabular}

would need additional support; people need more will power; Samoans have a different mind-set.

Most stated that the number of text messages were about right $(58,81 \%)$, with $11(15 \%)$ saying there were not enough messages, and only 2 (3\%) saying there were too many (one participant did not answer this question). When asked if they would pay for this programme, 22 (31\%) said they would and 46 (64\%) said they would not.

\section{DISCUSSION}

TXTTaofiTapaa is a text messaging cessation programme that was adapted from a proven effective New Zealand developed mCessation programme. The adaptation process was a collaboration between the New Zealand based academic development team and key local stakeholders including the Samoa MoH, Samoa Cancer Society and other individuals (as described in 4). This non-randomised pilot trial has demonstrated that it is feasible to deliver such a programme in Samoa. Despite some initial technical difficulties in delivering the text messages across the two mobile network operators, this issue was resolved and the programme was successfully delivered by a local MNO to 72 participants across the country.

The trial also showed that the programme was acceptable to Samoan smokers, recruiting participants quickly and receiving positive feedback from the majority of participants. Ninety-three per cent of participants who received the programme said they would recommend it to others and most (85\%) said they felt it would be effective for Samoans. Three-quarters (78\%) said they found the messages to be encouraging, and two-thirds (67\%) said they provided good advice on how to avoid smoking again and made them think about their family and loved ones (63\%).

This was not an effectiveness trial but participants were asked if they had stopped smoking during the study (40\% reported being abstinent for seven days at 1-month followup). Participants also reported that they felt the programme had helped them to stop smoking (43\%). This is similar from one month self-reported quit rates in other mCessation studies worldwide. In the original New Zealand study of the programme that TXTTaofiTapaa is based on (STOMP), the 6 -week point prevalence was $28 \%{ }^{8}$ In the UK adapta- 


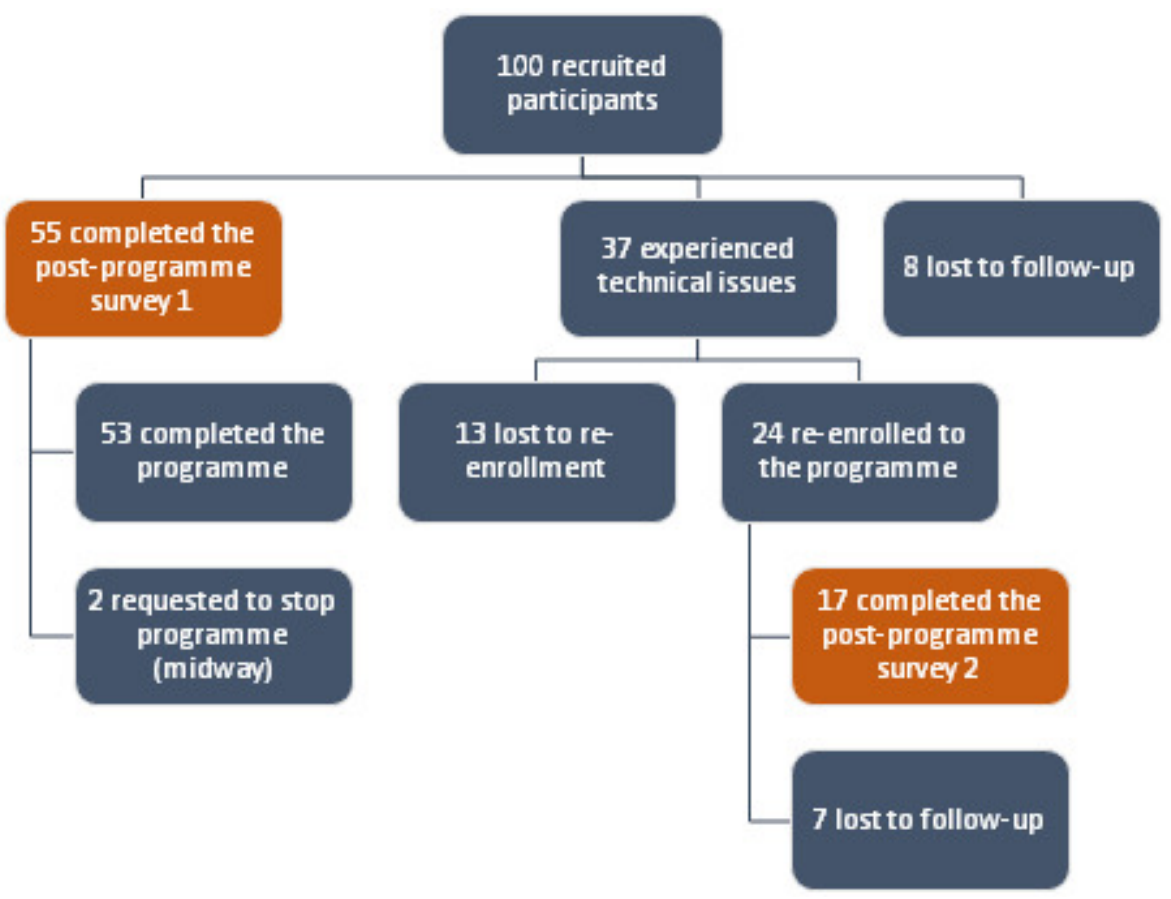

Figure 2. Flowchart of participants.

Table 2. Participant perspectives on how TXTTaofiTapaa helped them

\begin{tabular}{lcc}
\hline Did this programme help you do any of the following? (could choose more than one) & $\mathrm{N}=\mathbf{7 2}$ & $\%$ \\
\hline Think about quitting smoking & 47 & 65 \\
Try to quit at least once & 37 & 51 \\
Learn things that might help you to stop smoking in the future & 32 & 44 \\
Stop smoking & 31 & 43 \\
Encourage others you know to stop smoking & 23 & 32 \\
Reduce the number of cigarettes you smoke & 34 & 47 \\
Make changes to have a healthy lifestyle & 25 & 35 \\
Helped me save money & 4 & 6 \\
\hline
\end{tabular}

tion of STOMP, the Txt2Stop study of 5800 people, the selfreported 7 -day abstinence rate at 4 weeks was $28.7 \% .{ }^{10}$

We found this result to be very encouraging in a country without the broad organised tobacco control efforts that support cessation services in most developed nations where these programmes have been found to be effective. This provides an indication that it might be worth the Samoan MoH pursuing a scaling up of the programme and evaluating its effectiveness. The only published mCessation quit rate from an LMIC is from an evaluation of the national implementation of mCessation programme in India. ${ }^{15}$ However the outcome is substantially different - 30 day abstinence at 4-6 months - and so it is hard to compare with our findings.

mCessation programmes have been found to be effective in many randomised controlled trials (RCTs) in many different contexts, ${ }^{16}$ therefore, a further RCT may not be required. However, the difference here is the delivery in a country with little experience of mHealth and with little tobacco control support for cessation. The benefit of using mobile phones to deliver such programmes is that the mo- bile phone has penetrated into all corners of all societies. Ministries of Health that may not have the delivery networks or resources for in-person or even phone counselling support for smoking cessation, may yet be able to implement a text messaging cessation programme. It is comparably cheaper, ${ }^{17}$ uses ubiquitous existing infrastructure (the mobile network), and is delivered by a device that is in almost every hand worldwide. ${ }^{18}$ It is important that large scale implementations of such programmes, particularly in LMICs, fully evaluate the real world impact on those who need them most.

This is not to underestimate the challenges in delivering an mCessation programme in this context. We encountered many complexities, including early and on-going local investment in the programme due to competing demands; ensuring all of the relevant stakeholders were identified and meaningfully involved; deploying international funding; employing local staff; building and maintaining local support between visits by the international team; agreement on appropriate text language. These factors are absolutely critical to ensuring that if effective, the programme 
Table 3. Aspects of the messages that were liked and disliked

\begin{tabular}{|c|c|c|}
\hline What did you like about the messages you received? (could choose more than one) & $\mathrm{N}=72$ & $\%$ \\
\hline They were encouraging & 56 & 78 \\
\hline Helped me think about my family and loved ones & 45 & 63 \\
\hline Gave good advice on what to do to avoid smoking again & 48 & 67 \\
\hline Gave me tips on how to have a healthier lifestyle & 45 & 63 \\
\hline Gave me information about the effects of smoking & 45 & 63 \\
\hline Helped me save money & 3 & 4 \\
\hline Gave reminders to stay quit & 2 & 3 \\
\hline \multicolumn{3}{|l|}{ Did you dislike the content of the text messages? } \\
\hline Yes & 3 & 4 \\
\hline No & 68 & 94 \\
\hline No answer & 1 & 1 \\
\hline \multicolumn{3}{|l|}{ If yes, why? } \\
\hline Some messages were repetitive & 1 & \\
\hline I don't like the way some messages were written & 1 & \\
\hline SMS not helping & 1 & \\
\hline
\end{tabular}

can be integrated into the health system, including financing and governance.

\section{LIMITATIONS OF THIS STUDY}

This was a pragmatic pilot trial that had to deal with the difficulties of implementing a novel initiative. This included delivering a text messaging health content (mHealth) programme in a country with little MNO experience or expertise, leading to the perhaps inevitable technical issues affecting our ability to obtain full follow up data. Multiple attempts were made to include all participants in the final results but we were unable to follow up with all. Finally, this study was designed as a non-randomised pilot trial to demonstrate the feasibility and acceptability to potential funders and implementers. Therefore, it does not adequately demonstrate effectiveness of the programme.

This study found that it was feasible to deliver an adapted mCessation programme locally in Samoa. The programme was well accepted by those who received it, and they perceived it to be useful in helping them stop smoking. Self-reported quitting was high. As mCessation programmes have been proven effective in many different contexts, we do not believe that another randomised controlled trial would be warranted. We continue to work with the Samoa MoH to encourage them to make the programme available nationally. For this purpose, a cost-effectiveness analysis is being prepared. Once implemented, the programme would be evaluated in the real world context for its impact on quitting rates and smoking prevalence in Samoa.

\section{CONCLUSIONS}

Delivering a text message cessation programme (TXTTaofiTapaa) in Samoa is feasible, and smokers in Samoa appear to find it to be both acceptable and helpful.

\section{ACKNOWLEDGEMENTS}

The authors would like to thank the Ministry of Health of the Government of Samoa, especially Dr Take Naseri, Maee Ualesi Silva, Siufuga Simi, and Faaifaso Moala. We would also like to thank Kilisitina Best for assisting with the major part of the data gathering.

\section{DISCLAIMER}

The views expressed in the submitted article are the authors' own and not an official position of the institution or funder.

\section{FUNDING}

This work was supported by the Health Research Council of New Zealand (13-1002) and the New Zealand Ministry of Foreign Affairs and Trade (A11689-A01).

\section{COMPETING INTERESTS}

All authors have completed the Unified Competing Interest form at http://www.icmje.org/coi_disclosure.pdf (available on request from the corresponding author). None of the participating authors has a conflicting financial or other interest related to the work detailed in this manuscript.

\section{CORRESPONDENCE TO:}

Associate Professor Robyn Whittaker, MBChB, MPH, PhD

National Institute for Health Innovation

School of Population Health

University of Auckland

Private Bag 92019

Auckland Mail Centre

Auckland 1142

New Zealand

r.whittaker@auckland.ac.nz 
This is an open-access article distributed under the terms of the Creative Commons Attribution 4.0 International License (CCBY-4.0). View this license's legal deed at http://creativecommons.org/licenses/by/4.0 and legal code at http://creativecommons.org/licenses/by/4.0/legalcode for more information. 


\section{REFERENCES}

1. Rasanathan $\mathrm{K}$, Tukuitonga $\mathrm{C}$. Tobacco smoking prevalence in Pacific Island countries and territories: a review. $N Z$ Med J. 2007;120:U2742.

2. Kessaram T, McKenzie J, Girin N, et al. Tobacco Smoking in Islands of the Pacific Region, 2001-2013. Prev Chronic Dis. 2015;12:E212. doi:10.5888/pcd12.15 $\underline{0155}$

3. World Bank. Pacific Islands: Non-Communicable Disease Roadmap. Accessed January 22, 2019. htt p:/www.worldbank.org/en/news/feature/2014/07/11/ pacific-islands-non-communicable-disease-roadmap

4. Linhart C, Naseri T, Lin S, et al. Tobacco smoking trends in Samoa over four decades: can continued globalization rectify that which it has wrought? Global Health. 2017;13:31. doi:10.1186/s12992-017-02 56-2

5. World Health Organization. Samoa STEPS Survey 2013. In: STEPS Report. World Health Organization; 2015.

6. World Health Organization Regional Office for the Western Pacific. Regional Action Plan for the Tobacco Free Initiative in the Western Pacific (2015-2019). World Health Orgaisation; 2015.

7. Government of Samoa. Health Sector Plan 2008-2018. Ministry of Health; 2008.

8. Colantonio LD, Peña L, Whittaker R, Mejia RM. Cross-Cultural Adaptation of a Text Message-Based Program for Smoking Cessation in Buenos Aires, Argentina. Nicotine Tob Res. 2016;18(3):314-320. do i:10.1093/ntr/ntv061

9. Rodgers A, Corbett T, Bramley D, Riddell T, Wills M, Lin RB. Do u smoke after txt? Results of a randomised trial of smoking cessation using mobile phone text messaging. Tob Control. 2005;14(4):255-261. doi:10.1136/tc.2005.011577
10. Free C, Whittaker R, Knight R, Abramsky T, Rodgers A, Roberts IG. Txt2stop: a pilot randomised controlled trial of mobile phone-based smoking cessation support. Tob Control. 2009;18(2):88-91. do i:10.1136/tc. 2008.026146

11. McCool J, Tanielu H, Umali E, Whittaker R. Assessing the cross-cultural adaptation and translation of a text-based mobile smoking cessation program in Samoa (TXTTaofiTapaa): Pilot study. JMIR Mhealth Uhealth. 2018;6(8):e173. doi:10.2196/mhealt h.9033

12. Tanielu H, McCool J, Umali E, Whittaker R. Samoan smokers talk about smoking and quitting: A focus group study. Nicotine Tob Res. 2018;20(9):1132-1137. doi:10.1093/ntr/ntx152

13. GSMA. The Mobile Economy: Asia Pacific 2014. Published 2015. Accessed January 22, 2019. https://w ww.gsmaintelligence.com/research/2014/06/c0e1063f 5f4eed14d3a2d0d8473cf7e8/468/

14. Samoa Bureau of Statistics. 2016 Census Brief No. 1. Samoa Bureau of Statistics; 2017.

15. Gopinathan P, Kaur J, Joshi S, et al. Self-reported quit rates and quit attempts among subscribers of a mobile text messaging-based tobacco cessation programme in India. BMJ Innov. 2018;4(4):147-154. $\underline{\mathrm{d}}$ oi:10.1136/bmjinnov-2018-000285

16. Whittaker R, McRobbie H, Bullen C, Rodgers A, Gu Y. Mobile phone-based interventions for smoking cessation. Cochrane Database Syst Rev. 2016;4:CD006611. doi:10.1002/14651858.CD006611.p $\underline{\mathrm{ub} 4}$

17. Guerriero C, Cairns J, Roberts I, Rodgers A, Whittaker R, Free C. The cost-effectiveness of smoking cessation support delivered by mobile phone text messaging: Txt2stop. Eur J Health Econ. 2013;14(5):789-797. doi:10.1007/s10198-012-0424-5

18. International Telecommunication Union. ICT Facts and Figures 2017. Accessed January 22, 2019. htt ps://www.itu.int/en/ITU-D/Statistics/pages/facts/defa ult.aspx 